\title{
GLOBAL LEARNING AND ITS IMPLEMENTATION
}

\author{
Marion G. Ben-Jacob ${ }^{1}$ and David Y. Wang ${ }^{2}$ \\ ${ }^{1}$ Ph.D. \\ ${ }^{2} E d . D$. \\ Mercy College, 555 Broadway, Dobbs Ferry, New York, 10522, USA
}

\begin{abstract}
Global learning is concerned with intercultural and international aspects of education as well as specific content areas. Technological advances support students from different countries, backgrounds, and cultures to study and learn together, and enhance their pedagogical and life experiences. Global learning is critical for educators as well as students in order to embrace world cultures and events and develop as citizens of the world. This paper provides a background into global learning. The generic goals of global learning and the technology that can implement, facilitate, and sometimes impede them are discussed.
\end{abstract}

\section{KEYWORDS}

Global Learning, Benefits, Education, Technology

\section{INTRODUCTION}

Global learning is the collaboration for the attainment of knowledge that surpasses national boundaries. It is international, and both multicultural and intercultural. It supports tolerance and diversity. It provides varied perspectives on politics, religion, ethnicity, and race. Connections between subject matter and future careers and society are formed. The world today is complex and greater understanding among different countries and their populations is necessary. Students need to recognize interdependencies and promotion of social justice in a worldwide context. Global education is a stepping-stone for universal acceptance and peace. It promotes progress toward the unity of man as well as the enhancement of content learning (Education Transforms Lives, 2019).

The goals of global learning include the generating of new knowledge about global studies, the encouraging of greater civic engagement and social responsibility, the cultivation of intercultural skills and the necessary technical skill expansion and training. This includes greater knowledge of the historical, political, cultural and socioeconomic connections among the world, identification of the processes by which civilizations are defined now and in the past, and investigation of the dynamics of global transactions of various types (Kahn \& Agnew, 2015).

We need to inculcate our students with civic awareness and respect so they may become citizens of the world. Global education promotes a heightened sense of international connections and interdependencies, a heightened sense of the power of individual intervention in a global situation, identification of ethical and moral questions from an international perspective, identifications of international as well as national obligations. The future requires the ability to traverse cultural borders with greater skill, the ability to view issues from different perspectives, the capability to work effectively with people from different backgrounds and beliefs, and greater tolerance for differences (Global Dimensions, 2019; Kahn \&Agnew, 2015).

As global educators, we need to support our students analyzing situations across different areas of information. We need to guide our students in applying their knowledge to new local and global environments and to discern the similarities and differences between the two. We need to support their analysis of the ethical and moral issues, including those pertaining to technology. Furthermore, we need to share pedagogical strategies that work for all students. Different learning styles that need to be addressed are not local in nature, but rather worldwide (Education Transforms Lives, 2015; Global Dimensions, 2019). 


\section{BODY OF PAPER}

\subsection{The Implementation}

Many innovations in today's educational environment incorporate technology to an extensive degree. Indeed, technology supports a global learning community. Technology has facilitated greater collaboration and dialogue among participants who are interested in advancing global learning and learning in general. We are able to share research, pedagogy, and learning with colleagues and students both geographically close and remote. Technology has bridged temporal and geographic disparities.

\subsection{Technological Perspectives}

For the most part, technology promotes and enhances global learning. The Internet and the World Wide Web are the underlying platforms for global learning channels and environments. The cost to promote global learning is relatively low over the computer networks, and yet, the audience it can reach is massive. Courseware, like Blackboard or Moodle, is the vehicle driving global learning (Blackboard, 2019; Moodle, 2019). Courseware provides secure login, discussion templates, internal emails, homework postings and submissions, exam monitoring, student activity logs, and many other assessment functions (Blackboard, 2019; Moodle, 2019). Technology creates courseware as a virtual classroom with all the tools needed and without the physical walls and doors. Digital learning tools, e.g. Cengage's MindTap or Pearson's MyLab, assist teachers to plan lessons, utilize test banks, monitor student progress, and perform tasks usually done with pencils and papers without technology (Cengage, 2019; Pearson, 2019). Blogs, webcasts, social media, invitation-only video and audio meeting software, like Zoom or Skype, are not subject to geographical boundaries; they facilitate seamless communications, protect academic freedom, and make the global learning experience truly multi-media focused and cost-effective (Zoom, 2019; Skype 2019). On the other hand, technology can be implemented by governments or certain organizations to impede global learning. Some governments employ technology to censor dissident scholars, monitor opponents' daily activities, and even shut down the entire Internet services in their perspective nations. In recent years, technology has become a double-edged sword for global learning. Many innovations in today's educational environment incorporate technology to an extensive degree. Indeed, technology supports a global learning community. Technology has facilitated greater collaboration and dialogue among participants who are interested in advancing global learning and learning in general. We are able to share research, pedagogy, and learning with colleagues and students both geographically close and remote. Technology has bridged temporal and geographic disparities.

\subsection{Ethical Perspectives}

The growth of global learning communities and the incorporation of technology into the learning environment require appropriate ethical behavior when using and taking advantage of these educational boons. People need to be familiar with different concerns and issues, including, just to name a few, the following: the liability of publishing false or private information on the Internet, the format of Internet citations, fair use and copyright, computer-use guidelines, and the evaluation of Web information. Plagiarism as a concept needs to be addressed from different perspectives, including that of sociological background. Part of understanding and accepting differences in populations is to be ready to lay a foundation that one might have taken for granted in a homogeneous environment. 


\subsection{Pedagogical Perspectives}

From a global perspective, educators are seeking to enhance the education of our students. There are different types of learners and different cultures at different institutions. Global learning fosters networking for academic improvement and builds upon these differences.

The culture of an institution with regard to the scholarship of pedagogy and learning needs to be strong. This is important from a local perspective but even more so from a global perspective because of all the additional considerations. If the faculty does not believe in its importance, given the possible consequences, the culture of the institution needs to be changed. The fundamental way of accomplishing this is by establishing expectations, providing support, and then assessing and rewarding the faculty (Global Dimensions, 2019).

\section{CONCLUSION}

We are now part of a global knowledge community. When one speaks of global learning, it is for students and instructors as well. We are living in a remarkable time for education and the enhancement of pedagogy. Ideas, thoughts and knowledge can be readily shared. We need to take advantage of the opportunities offered to us. We are citizens of the world.

\section{REFERENCES}

Blackboard. (2019). Blackboard, Inc. (Accessed 2 December 2019) < http://www.blackboard.com/>

Cengage. (2019). Cengage. (Accessed 2 December 2019) <www.cengage.com>

Education Transforms Lives. (2019). UNESCO. (Accessed 3 December 2019) < https://en.unesco.org/themes/education/>

Global Dimension... the world in your classroom. (2019). Reboot the Future. (Accessed 8 December 2019) https://www.rebootthefuture.org/

Kahn, Hilary \& Agnew, Melanie, (2015), Global Learning Through Difference: Considerations for Teaching, Learning, and the Internationalization of Higher Education. Journal of Studies in International Education. (Accessed 5 December 2019) < https://journals.sagepub.com/doi/abs/10.1177/1028315315622022?.journalCode=jsia>

Moodle (2019). (Accessed 2 December 2019) <https://moodle.org/>

Pearson (2019). Pearson. (Accessed 2 December 2019) <https://www.pearson.com/>

Richlin, Laurie \& Cox, Milton. (2004) "Developing Scholarly Teaching and the Scholarship of Teaching and Learning Through Faculty Learning Communities." New Directions for Teaching and Learning. No.97. Wiley Periodicals, Inc. Spring 2004

Skype. (2019). (Accessed 2 December 2019) <https://www.skype.com/en/>

Zoom. (2019). (Accessed 2 December 2019) <https://zoom.us/> 